\title{
Analisis Perbandingan Unjuk Kerja Motor Bensin Dengan Penambahan Groundstrap dengan Material Tembaga Dan Perak Pada Kabel Koil Busi
}

\author{
Hardian Putra Wijaya*, K Rihendra Dantes, I Gede Wiratmaja \\ Progam Studi Pendidikan Teknik Mesin, Fakultas Teknik dan Kejuruan, Universitas \\ Pendidikan Ganesha, Singaraja, Indonesia \\ *Penulis korespondensi: putrahardian007@gmail.com
}

Histori artikel: diserahkan 15 Januari 2021, direviu 02 Februari 2021, direvisi 20 Maret 2021

\begin{abstract}
This research aimed to (1) Determining the differences in power and torque to use of a coil standard, a copper, and silver wire ground strap variation coils. (2) Determining the color characteristics of the sparks' size generated from the use of standard coils, variation coils of copper, and silver ground strap. This research used an experimental method. The data analysis technique used descriptive analysis, namely, observing and recording the test results and then concluding in tables and graphs. The test results show that an increase in power, and torque is generated in this test. The highest results were obtained using a silver ground strap variation coil with a power of $11.3 \mathrm{hp}$ and torque of $12.05 \mathrm{Nm}$. In this case, the percentages are $7.6 \%$ and $7.8 \%$ from the lowest results of the standard coil. There are different colors, sizes, and characters obtained in the test of sparks. The dark blue-purplish sparks color is obtained from the silver wire ground strap variation coil, which can increase motor performance in a motorcycle. These results suggest that the ground strap on the spark plug coil wire can provide an increment in engine performance.
\end{abstract}

Keywords: Coil, Groundstrap, Torque

DOI $\quad$ : https://doi.org/10.18196/jqt.v2i2.10787

WEB : https://journal.umy.ac.id/index.php/qt/article/view/10787

\section{PENDAHULUAN}

Transportasi darat merupakan jenis yang masih banyak diminati masyarakat Indonesia. Jenis sepeda motor merupakan salah satu sarana yang paling banyak digunakan terutama di kota-kota besar seperti Jakarta, Surabaya, Yogyakarta, Semarang, Denpasar dan dikotakota lain. Hal ini disebabkan penggunaan sepeda motor dirasa praktis untuk melalui padatnya lalu lintas di daerah kota. Di daerah pedesaanpun sepeda motor banyak digunakan sebagai pendukung aktivitas bepergian ke kota yang menempuh jarak jauh. Teknologi pada sepeda motorpun kian semakin berkembang. Performa dan efesiensi merupakan faktor konsumen dalam memilih jenis sepeda motor yang diminati. Performa mesin yang baik dan efesiensi bahan bakar didukung oleh sistem pengapian yang baik pula. Sistem pengapian merupakan sistem komponen yang sangat penting pada sepeda motor. Menurut Jama et al. (2008b), sistem pengapian pada motor bensin berfungsi mengatur proses pembakaran campuran bensin dan udara di dalam silinder pada langkah kompresi. Sistem pengapian ini sangat berpengaruh pada daya, torsi dan konsumsi bahan bakar yang dibangkitkan oleh mesin tersebut. Sistem pengapian khususnya pada motor bensin 4 langkah telah mengalami banyak penyempurnaan. Pada saat awal sepeda motor mulai diproduksi sistem pengapian pada motor bensin menggunakan sistem pengapian konvensional. Sistem ini menggunakan platina sebagai bahan atau materialnya. Bahan ini berfungsi untuk memutus dan menghubungkan tegangan baterai ke kumparan primer sehingga disebut dengan contact breaker. Jenis ini banyak ditemukan pada sepeda motor yang masih menggunakan sistem karburator. Sistem karburator dengan pengapian konvensional platina menghasilkan daya dan torsi kurang maksimum dan konsumsi bahan bakar yang tinggi, terutama pada putaran idle. 
Sistem karburator memerlukan bahan bakar awal agar dapat hidup dikarenakan temperatur yang rendah sehingga pada kondisi ini bahan bakar terbakar tidak sempurna akibatnya konsumsi bahan bakar meningkat.

Sepeda motor saat ini telah berubah menggunakan sistem injeksi, sehingga penggunaan konsumsi bahan bakar dapat dikontrol. Sistem pengapian dengan sistem injeksi dibekali sistem pengapian yang lebih baik yaitu CDI (Capacitor Discharge Ignition). Sepedda motor saat ini ada dua jenis yaitu tipe manual dan matic. Tipe transmisi manual merupakan tipe yang banyak digunakan pada komponen masyarakat karena dianggap memiliki perfoma yang lebih dibandingkan penggunaan sepeda motor matic.

Sistem pengapian pada sepeda motor banyak terjadi pada koil pengapian terdapat adanya medan magnet yang tidak diketahui hal ini dapat menurunkan loncatan percikan bunga api yang dihasilkan dalam busi kecil sehingga sistem pembakaran dalam tidak sempurna serta dapat menurunkan performa mesin pada umumnya. Untuk memaksimalkan sistem pengapian maka yang harus dilakukan adalah dengan mengganti ignition koil standar dan dimodifikasi dengan penambahan alat yang dapat membuat arus listrik menjadi lebih stabil dan juga dapat menghasilkan percikan bunga api pada busi lebih lebih besar dan fokus. Alat tersebut yaitu Ignition booster. Berbagai jenis dari ignition booster salah satunya adalah Groundstrap. Menurut Isnadi et al. (2014) Groundstrap merupakan salah jenis ignition booster yang fungsinya menstabilkan arus listrik yang dihasilkan koil sehingga percikan busi bisa lebih besar, fokus dan stabil. Penggunaan groundstrap juga lebih maksimal dikarenakan groundstrap dapat dimodifikasi dengan penggantian material dan jumlah lilitan. Hambatan jenis yang semakin kecil akan semakin baik dalam menghantarkan arus arus listrik. Hal ini sejalan dengan yang dikemukakan oleh Parhan (2013) bahwa selain bahan dan jumlah lilitan groundstrap pada kabel busi juga dapat mempengaruhi besarnya kemagnetan yang dihasilkan. Menurut penelitian oleh Ndoen et al. (2019) ketahanan busi juga merupakan faktor yang penting dalam menentukan performa kendaraan. Jenis busi saat ini banyak varian sehingga perlu dikaji penggunaannya. Hasil penelitian ini menunjukkan bahwa dari ketiga jenis busi yang diteliti yaitu Denso, NGK dan Iridium masing-masing jenis busi memiliki karakteristik dan warna percikan bunga api yang berbeda-beda, hal ini disebabkan karena bahan atau material yang digunakan pada busi tersebut berbeda. Hasil yang didapat tahanan busi Iridium paling kecil yaitu $0,2 \Omega$ sedangkan Denso $0,4 \Omega$ dan paling besar adalah NGK $0,6 \Omega$. Hal ini sejalan dengan hasil pijaran busi Iridium yang berwarna biru keungguan $\left(9500-10.000^{\circ} \mathrm{K}\right)$ dengan bentuk pijaran fokus, Denso berwarna putih kebiruan (7000-7500 $\left.{ }^{\circ} \mathrm{K}\right)$ menyebar, dan terakhir adalah busi NGK dengan warna pijaran biru (8500$9000{ }^{\circ} \mathrm{K}$ ) menyebar. Kesimpulan busi Iridium merupakan jenis busi yang direkomendasikan karena memilii tahanan kecil dan pijaran fokus sehingga meningkatkan pembakaran.

Pemilihan bahan pada groundstrap merupakan salah satu faktor yang menentukan maksimal tidak nya groundstrap. Menurut Buntarto (2015) hambatan dipengaruhi oleh tiga faktor, yaitu panjang, luas, dan jenis bahan. Hambatan suatu bahan dipengaruhi salah satunya oleh nilai hambatan jenis bahan tersebut. Sebuah kawat tembaga memiliki nilai hambatan jenis adalah $1,68 \times 10^{-8}$ dan hambatan jenis perak $1,59 \times 10^{-8}$ ohm.m. semakin kecil nilai hambatan jenis akan semakin baik mengalirkan arus listrik. Suatu bahan penghantar dengan tahanan jenis kecil menghantarkan arus listrik dengan baik (Parhan et al., 2013). Jumlah lilitan groundstrap pada kabel busi juga dapat mempengaruhi nilai tahanan dan juga besarnya kemagnetan yang dihasilkan. Penelitian yang dilakukan oleh Isnadi (2014), menyimpulkan penggunaan groundstrap menghasilkan torsi maksimum sebesar $8,89 \mathrm{Nm}$ dan daya maksimum sebesar 8,37 Hp, dari kondisi standar yang hanya memiliki torsi maksimum $8,59 \mathrm{Nm}$ dan daya maksimum 8,30 $\mathrm{Hp}$. Penggunaan ignition booster berupa pemasangan groundstrap mampu mnstabilkan arus sehingga menigkatkan tekanan kompresi. Menurut Purnomo \& Munahar (2019) peran tekanan kompresi yang meningkat mampu menghemat penggunaan bahan bakar pada sepeda motor. Penambahan Kawat Berbahan Material dari tembaga dan perak pada kabel koil busi diharapkan mampu meningkatkan nilai daya dan torsi. Koil dari bahan tersebut akan dibandingkan dengan unjuk kerja motor bensin dengan penggunaan koil standar. 


\section{METODE}

Metode dalam penelitian ini menggunakan metode percobaan. Menurut Sugiyono (2012) Metode penelitian percobaan yaitu bertujuan mencari kebaruan dari pengaruh perlakuan atau rekayasa tertentu terhadap suatu objek penelitian pada kondisi tertentu yang terkendali. Pada penelitian ini, penulis lebih memilih untuk menggunakan metode percobaan. Langkah-langkah yang perlu diperhatikan dalam penelitian dengan percobaan adalah memilih parameter variable bebas yang akan dibandingkan dengan berdasar pada latar belakang masalah yang dihadapi selanjutnya adalah mencari tinjauan pustaka dari beberapa penelitian terdahulu yang pernah dilakukan. Terakhir adalah membuat diagram alir penelitian untuk memudahkan dalam membaca alur percobaan yang akan dilakukan pada umumnya mengelompokkan variabel tetap dan variabel bebas. pengelompokkan data yang didapat kemudian dianalisis sesuai atau tidak dengan hipotesis yang disusun. Dari masing-masing variasi dilakukan 3 kali pengujian pengambilan data, setelah mendapatkan hasil dari pengujian masing-masing variasi tersebut, selanjutnya data hasil uji dimasukkan kedalam tabel. Data tersebut dianalisis dengan menggunakan statistik deskriptif melalui gambar grafik dan tabel dengan menggunakan media software microsoft excel dalam bentuk grafik sehingga data hasil atau nilai yang di dapat lebih mudah dipahami dan dianalisis.

\section{HASIL DAN PEMBAHASAN}

Pada penelitian ini memperlihatkan hasil daya dan torsi pada penggunaan koil standar,koil variasi groundstrap kawat tembaga serta koil variasi groundstrap kawat perak.

TABEL 1. Hasil data daya dalam tiga kali pengujian

\begin{tabular}{|c|c|c|c|}
\hline \multirow[t]{2}{*}{$\begin{array}{r}\text { Putaran } \\
\text { Mesin }\end{array}$} & $\begin{array}{c}\text { Koil } \\
\text { Standar }\end{array}$ & $\begin{array}{c}\text { Koil Groundstrap } \\
\text { Tembaga }\end{array}$ & $\begin{array}{c}\text { Koil Groundstrap } \\
\text { Perak }\end{array}$ \\
\hline & Daya (Hp) & Daya (Hp) & Daya (Hp) \\
\hline \multirow{3}{*}{3000} & 4,4 & 4,5 & 6,7 \\
\hline & 4,4 & 4,5 & 4,9 \\
\hline & 4,6 & 5,5 & 8,1 \\
\hline Rata-rata & 4,6 & 4,8 & 6,5 \\
\hline \multirow{3}{*}{4000} & 6,2 & 6,3 & 8,6 \\
\hline & 6,1 & 6,3 & 6,4 \\
\hline & 6,2 & 8,7 & 8,9 \\
\hline Rata-rata & 6,1 & 7,1 & 7,9 \\
\hline \multirow{3}{*}{5000} & 8,0 & 8,4 & 10,3 \\
\hline & 7,9 & 8,4 & 8,4 \\
\hline & 8,0 & 9,0 & 10,7 \\
\hline Rata-rata & 7,9 & 8,4 & 9,8 \\
\hline \multirow{3}{*}{6000} & 9,8 & 10,1 & 10,4 \\
\hline & 9,8 & 10,1 & 10,3 \\
\hline & 10,6 & 10,3 & 11,4 \\
\hline Rata-rata & 10,0 & 10,1 & 10,7 \\
\hline \multirow{3}{*}{7000} & 10,3 & 11,1 & 11,2 \\
\hline & 10,5 & 11,0 & 11,2 \\
\hline & 10,7 & 10,7 & 11,6 \\
\hline Rata-rata & 10,5 & 10,9 & 11,3 \\
\hline \multirow{3}{*}{8000} & 9,9 & 11,0 & 11,1 \\
\hline & 10,1 & 10,7 & 11,0 \\
\hline & 10,1 & 11,3 & 11,4 \\
\hline Rata-rata & 10,0 & 11,0 & 11,1 \\
\hline \multirow{3}{*}{9000} & 9,5 & 10,7 & 10,1 \\
\hline & 9,6 & 10,3 & 10,7 \\
\hline & 9,9 & 10,8 & 10,8 \\
\hline Rata-rata & 9,6 & 10,6 & 10,5 \\
\hline
\end{tabular}


TABEL 2. Hasil data rata-rata daya mesin

\begin{tabular}{cccc}
\hline \multirow{2}{*}{$\begin{array}{c}\text { Putaran } \\
\text { Mesin }\end{array}$} & $\begin{array}{c}\text { Koil } \\
\text { Standar }\end{array}$ & $\begin{array}{c}\text { Koil Groundstrap } \\
\text { Tembaga }\end{array}$ & $\begin{array}{c}\text { Koil Groundstrap } \\
\text { Perak }\end{array}$ \\
\cline { 2 - 4 } & Daya (Hp) & Daya (Hp) & Daya (Hp) \\
\hline 3000 & 4,6 & 4,8 & 6,5 \\
\hline 4000 & 6,1 & 7,1 & 7,9 \\
\hline 5000 & 7,9 & 8,4 & 9,8 \\
\hline 6000 & 10,0 & 10,1 & 10,7 \\
\hline 7000 & 10,5 & 10,9 & 11,3 \\
\hline 8000 & 10,0 & 11,0 & 11,1 \\
\hline 9000 & 9,6 & 10,6 & 10,5 \\
\hline
\end{tabular}

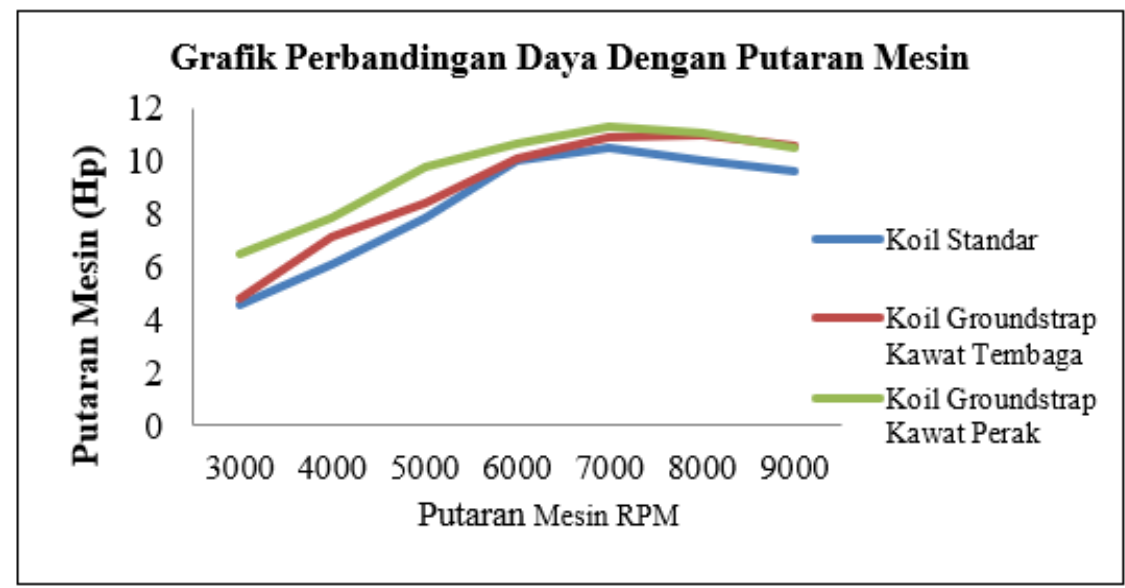

GAMBAR 1. Grafik Hubungan Daya Dengan Putaran Mesin

\section{Data Hasil Pengujian Daya}

Keterangan ini memperlihatkan perbedaan daya yang dihasilkan dalam pengujian koil standar, koil variasi groundstrap tembaga serta koil variasi groundstrap perak pada rentang putaran mesin $1000 \mathrm{rpm}$ pada jangkauan 3000 hingga 9000 RPM dan diambil datanya pada 3 kali pengulangan pengambilan data. Hasil tersebut dapat dilihat pada Tabel 1. Nilai pengujian kemudian dirata-rata dan diperoleh hasil seperti ditunjukkan pada Tabel 2. Gambar 1 menunjukkan hasil grafik uji perbandingan ketiga jenis koil.

Gambar 1. menunjukan hasil pengujian daya pada kinerja mesin motor Jupiter Mx 135cc dengan menggunakan koil standar, koil variasi groundstrap kawat tembaga dan koil variasi groundstrap kawat perak dengan putaran mesin terendah 3000rpm hingga putaran mesin maximal 9000rpm. Daya tertinggi diperoleh pada koil groundstrap kawat perak dengan nilai 11,3 Hp pada putaran mesin $7000 \mathrm{rpm}$. Koil groundstrap menghasilkan nilai daya dibawah koil grandstap perak yaitu pada daya $11,0 \mathrm{Hp}$ di putaran $8000 \mathrm{rpm}$ dan koil standar pada daya 10,5 Hp di putaran $7000 \mathrm{rpm}$.

Hasil ini menjelaskan adanya peningkatan daya yang dihasilkan. Persentase peningkatan daya yang dihasilkan dari penggunaan koil standar ke koil variasi groundstrap kawat tembaga sebesar $4,9 \%$ sedangkan peningkatan koil groundstrap perak sebesar 7,6\% dibandingkan dengan penggunaan koil standar.

Hasil pengujian ini sejalan dengan pengujian yang dilakukan sebelumnya oleh Triatmojo (2016). Pengaruh pemasangan ignition booster terhadap unjuk kerja mesin, hasil penelitian yang didapat menyimpulkan bahwa untuk mendapatkan daya dan torsi terbesar serta konsumsi bahan bakar yang rendah dapat dilakuakn dengan memodifikasi sistem pengapian. 
TABEL 3. Hasil data torsi dari tiga kali pengujian

\begin{tabular}{|c|c|c|c|}
\hline \multirow{2}{*}{ Putaran Mesin } & Koil Standar & $\begin{array}{l}\text { Koil Groudstrap } \\
\text { Tembaga }\end{array}$ & $\begin{array}{c}\text { Koil Groundstrap } \\
\text { Perak }\end{array}$ \\
\hline & Torsi (N.m) & Torsi (N.m) & Torsi (N.m) \\
\hline \multirow{3}{*}{3000} & 9,75 & 10,09 & 10,99 \\
\hline & 9,78 & 10,67 & 8,31 \\
\hline & 10,22 & 9,48 & 8,36 \\
\hline Rata-rata & 9,91 & 10,08 & 9,22 \\
\hline \multirow{3}{*}{4000} & 10,49 & 10,67 & 11,24 \\
\hline & 10,31 & 11,36 & 9,07 \\
\hline & 10,38 & 10,67 & 8,71 \\
\hline Rata-rata & 10,39 & 10,90 & 9,67 \\
\hline \multirow{3}{*}{5000} & 10,87 & 11,36 & 11,68 \\
\hline & 10,73 & 11,49 & 11,47 \\
\hline & 10,90 & 11,80 & 12,06 \\
\hline Rata-rata & 10,83 & 11,55 & 11,73 \\
\hline \multirow{3}{*}{6000} & 11,10 & 11,49 & 11,98 \\
\hline & 11,12 & 11,55 & 12,04 \\
\hline & 11,29 & 11,74 & 12,13 \\
\hline Rata-rata & 11,17 & 11,59 & 12,05 \\
\hline \multirow{3}{*}{7000} & 10,12 & 11,00 & 11,78 \\
\hline & 10,35 & 11,00 & 11,77 \\
\hline & 10,14 & 11,09 & 11,18 \\
\hline Rata-rata & 10,20 & 11,03 & 11,57 \\
\hline \multirow{3}{*}{8000} & 8,57 & 10,81 & 11,04 \\
\hline & 8,72 & 10,81 & 11,02 \\
\hline & 10,41 & 11,09 & 10,84 \\
\hline Rata-rata & 9,23 & 10,90 & 10,96 \\
\hline \multirow{3}{*}{9000} & 7,35 & 9,21 & 9,56 \\
\hline & 7,40 & 9,21 & 11,00 \\
\hline & 10,12 & 9,34 & 9,82 \\
\hline Rata-rata & 8,29 & 9,25 & 10,12 \\
\hline
\end{tabular}

Bahan perak dan tembaga merupakan bahan memiliki nilai konduktivitas termal serta sifat bahan yang berbeda serta jenis penghantar yang terbaik.

\section{Data Hasil Pengujian Torsi}

Pembahasan Nilai Torsi yang dihasilkan dalam pengujian koil standar, koil variasi groundstrap tembaga serta koil variasi groundstrap perak pada rentang putaran mesin 1000 rpm yang dipaparkan pada Tabel 3. Pengambilan data torsi mesin sebanyak 3 kali pengulangan pengambilan data yang pada akhirnya diperoleh data rata - rata perbandingan torsi mesin antara koil dalam kondisi standar dengan koil groundstrap kawat tembaga dan kawat perak pada variasi putaran mesin 3000 RPM sampai dengan 9000 RPM.

Gambar 2 menunjukan hasil pengujian torsi pada kinerja mesin motor Jupiter Mx $135 \mathrm{cc}$ dengan menggunakan koil standar, koil variasi groundstrap kawat tembaga dan koil variasi groundstrap kawat perak dengan putaran mesin terendah $3000 \mathrm{rpm}$ hingga putaran mesin maximal $9000 \mathrm{rpm}$. Tabel 4 menunjukkan nilai torsi rata-rata yang di hasilkan dari penggunaan koil. Hasil tertinggi didapat pada variasi kawat perak dengan nilai 12,05 N.m pada putaran mesin $6000 \mathrm{rpm}$, nilai kedua sedikit lebih rendah pada koil variasi groundstrap kawat tembaga dengan nilai torsi yang dihasilkan 11,59 N.m pada putaran 6000 rpm dan koil standar menghasilkan torsi yang paling kecil yaitu 11,17 N.m pada putaran 6000 rpm.

Persentase peningkatan torsi yang dihasilkan dari penggunaan koil standar ke koil variasi groundstrap kawat tembaga sebesar $3,7 \%$ peningkatan yang terjadi, peningkatan penggunaan koil standar dengan koil groundstrap perak sebesar $7,8 \%$ dibandingkan dengan penggunaan koil standar. 
TABEL 4. Hasil Data Rata-rata Torsi Mesin

\begin{tabular}{cccc}
\hline \multirow{2}{*}{$\begin{array}{c}\text { Putaran } \\
\text { Mesin }\end{array}$} & Koil Standar & $\begin{array}{c}\text { Koil Ground strap } \\
\text { Tembaga }\end{array}$ & $\begin{array}{c}\text { Koil Gxoundstrap } \\
\text { Perak }\end{array}$ \\
\cline { 2 - 4 } & Torsi (Nm) & Torsi (Nm) & Torsi (Nm) \\
\hline 3000 & 9,91 & 10,08 & 9,22 \\
\hline 4000 & 10,39 & 10,90 & 9,67 \\
\hline 5000 & 10,83 & 11,55 & 11,73 \\
\hline 6000 & 11,17 & 11,59 & 12,05 \\
\hline 7000 & 10,20 & 11,03 & 11,57 \\
\hline 8000 & 9,23 & 10,90 & 10,96 \\
\hline 9000 & 8,29 & 9,25 & 10,12 \\
\hline Rata-rata & 10,00 & 10,75 & 10,76 \\
\hline
\end{tabular}

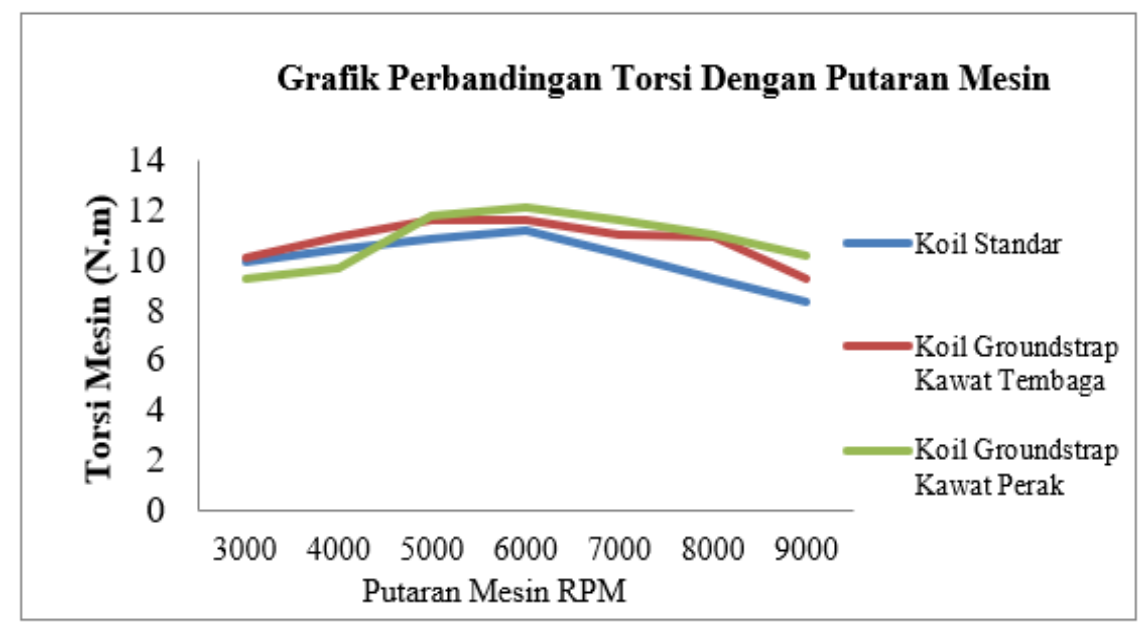

GAMBAR 2. Grafik Hubungan Torsi Dengan Putaran Mesin
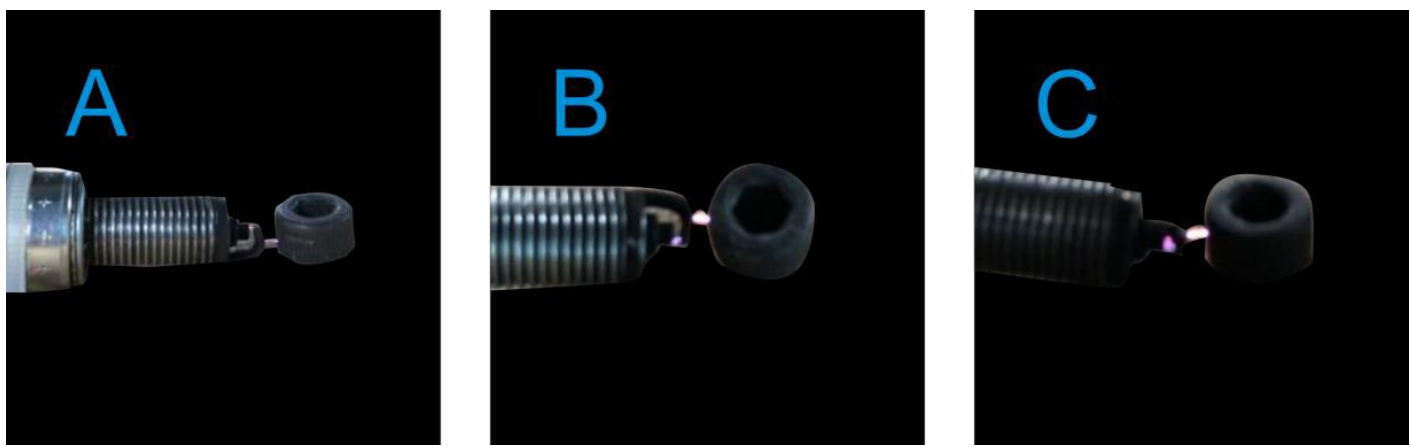

GAMBAR 3. Gambar Bunga Api Busi Koil Standar, Lilitan Tembaga, dan Perak

Hasil pengujian ini sejalan dengan pengujian yang dilakukan sebelumnya oleh Triatmojo (2016). Pengaruh pemasangan ignition booster terhadap unjuk kerja mesin, hasil penelitian yang didapat menyimpulkan bahwa untuk mendapatkan daya dan torsi terbesar serta konsumsi bahan bakar yang rendah dapat dilakukan dengan memodifikasi sistem pengapian agar lebih mendapatkan hasil maksimal dalam unjuk kerja motor.

\section{Hasil Percikan Bunga Api Busi}

Berikut ini merupakan hasil percikan bunga api busi yang dihasilkan sebagai berikut. Gambar 3 memperlihatkan pengujian percikan bunga api busi dengan penggunaan koil standar, koil variasi groundstrap kawat tembaga dan koil variasi groundstrap kawat perak. Di setiap masing-masing busi memiliki karakter, warna dan ukuran bunga api yang berbeda beda. Dimana hasil koil standar memiliki karakter warna merah serta memiliki 
ukuran kecil dalam hal pengukuran tabel warna suhu dapat dilihat sebesar $0^{\circ}-1800^{\circ} \mathrm{K}$, hasil koil variasi groundstrap kawat tembaga memiliki karakter warna biru kecil kemerahan serta memiliki ukuran meningkat dari koil standar dalam tabel warna suhu dapat dilihat sebesar $1800^{\circ}-5500^{\circ} \mathrm{K}$, dan hasil dari groundstrap kawat perak menghasilkan ukuran percikan bunga api yang besar memusat dan warna percikan api biru tua. Keungulan di bandingkan dengan 2 jenis koil lainnya. Warna biru tua tersebut menunjukan koil memiliki ukuran suhu sebesar $5500^{\circ}-$ $6500^{\circ} \mathrm{K}$. Kawat perak mampu menstabilkan arus listrik yang terjadi pada kabel koil terhadap busi serta menurunkan medan magnet sehingga arus listrik terjadi memusat besar. Menurut Purba (2018), selain penggunaan material perak dan tembaga pada groundstrap, peran pengaturan celah elektroda busi juga berpengaruh terhadap performa sepeda motor.

\section{KESIMPULAN}

Kesimpulan yang dapat diberikan pada pengunaan koil standar, koil variasi groundstrap kawat tembaga dan koil variasi groundstrap kawat perak, untuk unjuk kerja motor bensin 4 langkah sebagai berikut:

1. Daya tertinggi yang dihasilkan sebesar 11,3 Hp pada penggunaan koil groundstrap kawat perak, pada koil groundstrap kawat tembaga menghasilkan daya $11,0 \mathrm{Hp}$ naik sebesar $7,6 \%$ dan $4,9 \%$ dibandingkan penggunaan koil standar.

2. Torsi tertinggi yang dihasilkan sebesar 12,05 N.m pada penggunaan koil groundstrap perak, pada penggunan koil groundstrap tembaga sebesar 11,59 N.m naik sebesar 7,8\% dan 3,7\% dibandingkan penggunaan koil standar.

3. Warna percikan bunga api yang berbeda memiliki ukuran dan karakter masingmasing dari penggunaan koil standar, koil groundstrap tembaga dan koil groundstrap perak. Warna biru tua keunguan yang dihasilkan dari penggunaan koil groundstrap kawat perak ini memberikan hasil yang tertinggi sehingga dapat memberikan pengaruh terhadap unjuk kerja mesin sepeda motor. Pengaruh ini terjadi dikarenakan nilai hambatan yang dimiliki oleh perak lebih kecil sehingga lebih stabil.

\section{DAFTAR PUSTAKA}

Buntarto. 2015. Dasar-Dasar Kelistrikan Otomotif. Yogyakarta: Pustaka Baru Press

Isnadi, R., Bugis, Husin., Rohman, Ngatou. 2014. Pengaruh Pemasangan Groundstrap dengan Variasi Diameter Kawat Kumparan pada Kabel Busi dan Variasi Ignitiontiming terhadap Torsi dan Daya Pada Sepeda Motor Yamaha Jupiter Z Tahun 2007. Jurnal Nosel, $3(2)$.

Jama, J, \& Wagino. 2008b. Teknik Sepeda Motor Jilid 2 untuk SMK. Jakarta: Departemen Pendidikan Nasional

Ndoen, D., Suprapto, E. and Manesi, D., 2019. Analisis Kualitas Api Berbagai Merek Busi Berdasarkan Variasi RPM. Komodo Jurnal Pendidikan Teknik Mesin, 3(3), pp.175-179.

Parhan, N. 2013. Teknik Listrik. Malang: Kementrian Pendidikan dan Kebudayaan.

Purba, I.N., 2017. Analisa Pengaruh Variasi Celah Elektroda Busi Terhadap Performa Sepeda Motor Honda New Supra Fit 100 CC (Doctoral dissertation).

Purnomo, B.C. and Munahar, S., 2019. Pengaruh Tekanan Kompresi Terhadap Daya dan Torsi Pada Engine Single Piston. Quantum Teknika: Jurnal Teknik Mesin Terapan, 1(1), pp.14-18

Sugiyono. 2012. Metode Penelitian Kuantitatif Kualitatif dan $\mathrm{R}$ \& $\mathrm{B}$. Bandung: Alfabeta.

Triatmojo, B, D., 2016. Pengaruh Pemasangan Ignition Booster Pada Kabel Busi Dengan Variasi Koil Tehadap Performa Dan Konsumsi Bahan Bakar Pada Sepeda Motor. Skripsi. Jurusan Teknik Mesin Fakultas Teknik Universitas Negeri Semarang. 